\section{AB0739 MHAQ RESPONSE AMONG PATIENTS WITH PSORIATIC ARTHRITIS INITIATING A TNFI}

A. Ogdie ${ }^{1}$, L. Palmer ${ }^{2}$, D. Solomon ${ }^{3}$, A. Kavanaugh ${ }^{4}$, J. Greenberg ${ }^{2,5}$, ${ }_{\text {J. Curtis }}^{6}$, L. Harrold ${ }^{2,7}$, J. Kremer ${ }^{2,8}$, P. Mease ${ }^{9} .{ }^{1}$ University of Pennsylvania, Philadelphia, Pa; ${ }^{2}$ Corrona Research Foundation, Albany, NY; ${ }^{3}$ Brigham and Women's Hospital, Boston, MA; ${ }^{4}$ University of California San Diego, San Diego, $C A ;{ }^{5}$ New York University, New York, NY; ${ }^{6}$ University of Alabama, Birmingham, AL; ${ }^{7}$ University of Massachusetts, Worcester, MA; ${ }^{8}$ Albany Medical College, Albany, NY; ${ }^{9}$ Swedish Medical Center, Seattle, WA, United States

Background: Improved functional ability is among the most relevant outcomes for patients with psoriatic arthritis (PsA). ${ }^{1}$ The modified health assessment questionnaire (mHAQ) is one of the most commonly used patient reported outcome measures used in PsA and addresses the domains of disability and physical function.

Objectives: We examined the change in $\mathrm{mHAQ}$ over one year among patients with PsA initiating a TNFi and examined predictors of a clinically meaningful improvement in disability and physical function, as measured by the $\mathrm{mHAQ}$.

Methods: Patients with PsA enrolled in the Corrona Registry between 2005-2013 were followed from initiation of a TNFi (etanercept, adalimumab, infliximab, certolizumab, or golimumab) to the visit closest to 12 months. Patients were required to have at least three tender or swollen joints for inclusion for this study (this is not an inclusion criteria for Corrona), mHAQ within six months prior to TNFi initiation date, and at least one follow up visit 5-13 months after TNFi initiation with $\mathrm{mHAQ}$. The primary outcome was the proportion of patients with a decrease of 0.35 or more in the $\mathrm{mHAQ}$ score, the minimal clinically important improvement in $\mathrm{PsA}^{2}$. Predictors of $\mathrm{mHAQ}$ response were measured in the six months before TNFi initiation. Covariates with $\mathrm{p}$-value $\leq 0.10$ in univariable logistic regression models and $\leq 5 \%$ missing values were included in a multivariable model and removed individually until all remaining variables were significant $(p<0.05)$.

Results: Among 1742 TNFi initiations, 721 initiations (623 patients) met inclusion criteria. Mean age at initiation was 51.5 years (SD 12.3), $56 \%$ were female, median PsA duration was 5 years (IQR 2-11), and median baseline MHAQ was 0.375 (IQR 0.125-0.875). The mean change in $\mathrm{mHAQ}$ was -0.098 (SD 0.38) and median change in $\mathrm{mHAQ}$ was 0 (IQR: -0.25 to 0.125 ); $23 \%$ had a $\mathrm{mHAQ}$ decrease of 0.35 of more. In univariable models, college education and being married or partnered were inversely associated with MHAQ response (baseline scores were lower in patients with these characteristics) while patient global, patient pain, baseline clinical disease activity index (CDAl) and swollen joint count were positively associated with the outcome. However, in a multivariable model, only age (0.96 per year, $0.94-0.98)$ and baseline mHAQ score (17.7 per one point, 10.6-29.4) were associated with a decrease of 0.35 or more in the $\mathrm{mHAQ}$.

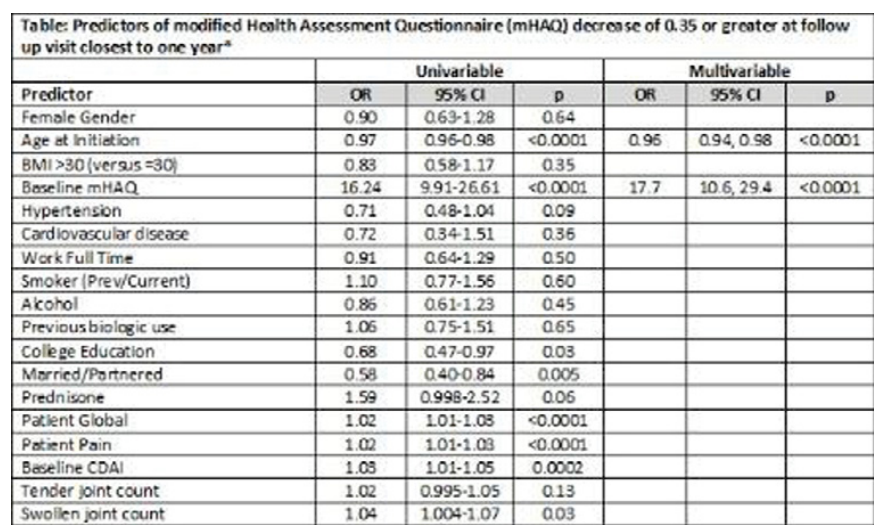

Conclusions: A clinically meaningful change in mHAQ occurred in $23 \%$ of patients and was strongly associated with age and baseline $\mathrm{mHAQ}$ score. In this real world population, there was little change in $\mathrm{mHAQ}$ scores over one year, despite treatment. These analyses are limited by the floor effect of the $\mathrm{mHAQ}$ among patients with established PsA. Despite having at least 3 tender and 3 swollen joints, many patients in this cohort had a low $\mathrm{mHAQ}$ at baseline which did not allow for sufficient change to meet the MCII.

References:

[1] Mease PJ et al. J Rheumatol 2011; 38:2461-5.

[2] Orbai AM et al. Ann Rheum Dis 2016; Epub.

Acknowledgements: This work was funded by the Corrona Research Foundation. Disclosure of Interest: A. Ogdie Grant/research support from: Pfizer (coinvestigator), Consultant for: Pfizer, Novartis, L. Palmer: None declared, D. Solomon Grant/research support from: Grants to BWH from amgen, lilly, bristol myers squibb, and pfizer, Consultant for: Corrona, LLC, A. Kavanaugh: None declared, J. Greenberg Shareholder of: Corrona, LLC, Consultant for: Genentech, Janssen, Novartis and Pfizer, Eli Lilly, Employee of: Corrona, LLC, J. Curtis: None declared, L. Harrold Shareholder of: Corrona LLC, Grant/research support from: Pfizer (to UMass), Consultant for: Roche, Employee of: Corrona LLC, UMass Medical School, J. Kremer Shareholder of: Corrona, LLC, Employee of: Corrona, LLC, P. Mease: None declared

DOI: 10.1136/annrheumdis-2017-eular.3547

\section{AB0740 SECUKINUMAB IN PSORIATIC ARTHRITIS: HIGH DISEASE BURDEN OBSERVED IN THE CORRONA PSORIASIS REGISTRY}

A.B. Gottlieb ${ }^{1}$, V. Strand ${ }^{2}$, C. Karki ${ }^{3}$, M. Mason ${ }^{3}$, J. Greenberg ${ }^{3}$, S. Jugl ${ }^{4}$, K.K. Gandhi ${ }^{5}$, P.J. Mease ${ }^{6} .{ }^{1}$ NY Medical College, New York; ${ }^{2}$ Stanford University School of Medicine, Stanford; ${ }^{3}$ Corrona LLC, Southborough, United States; ${ }^{4}$ Novartis Pharma AG, Basel, Switzerland; ${ }^{5}$ Novartis Pharmaceuticals Corp., East Hanover; ${ }^{6}$ Swedish Medical Center and University of Washington, Seattle, United States

Background: Secukinumab (SEC), a fully human anti-IL-17A monoclonal antibody, has significant efficacy in the treatment of moderate-to-severe psoriasis (Ps) and psoriatic arthritis (PsA), with a favourable safety profile. The Corrona Psoriasis Registry is an independent observational registry of Ps patients (pts) receiving FDA-approved systemic treatments (TNFis, anti-IL-17s and IL-12/23 and non-biologics) in the United States.

Objectives: To assess demographics, clinical features and pt reported outcomes (PROs) of Ps pts with concomitant PsA receiving systemic treatments at registry enrolment.

Methods: Adult Ps pts who initiated a systemic therapy at enrolment or in the previous 12 months, and concomitant PsA reported by a dermatologist, were included. Demographics (e.g. age, gender, BMI), disease activity (body surface area, investigator global assessment, psoriasis area severity index) and PROs (pain, fatigue, itch, EQ-VAS $0-100$, work productivity and activity impairment and dermatology life quality index) were evaluated at enrolment and stratified by therapy: SEC, etanercept (ETN), adalimumab (ADA), ustekinumab (UST), and non-biologics (Non-B).

Results: As of October-2016, 2073 Ps pts were enrolled in the registry; 823 $(39.7 \%)$ had a PsA diagnosis (mean disease duration 7.6 years) of which $37 \%$ were biologic naïve. Of the 823 pts with PsA, 25.4\% received SEC, $6.2 \%$ ETN, $21.5 \%$ ADA, $17.6 \%$ UST, and $24.8 \%$ Non-B. Pts on SEC had a mean age 53.2 years, mean BMI 32.4; $45 \%$ were female; all comparable across the treatment groups. PsA pts treated with SEC had higher Ps disease activity than other treated groups (Table). A higher proportion of SEC treated PsA pts had diabetes and cardiovascular disease ( $25 \%$ and $19 \%$ respectively). Mean pain scores were higher in the SEC group; however other PROs assessed at enrolment were similar across treatment groups (Table).

Table 1. Pt characteristics at enrolment ${ }^{1}$

\begin{tabular}{lcccccc}
\hline Mean \pm SD & SEC & ETN & ADA & UST & Non- $B^{*}$ & Overall \\
& $\mathrm{N}=209$ & $\mathrm{~N}=51$ & $\mathrm{~N}=177$ & $\mathrm{~N}=145$ & $\mathrm{~N}=204$ & $\mathrm{~N}=823$ \\
\hline $\mathrm{PASI}(0-72)^{\#}$ & $7.7 \pm 9.4$ & $4.0 \pm 4.0$ & $4.6 \pm 6.6$ & $5.0 \pm 5.9$ & $4.6 \pm 6.6$ & $5.5 \pm 7.4$ \\
IGA, (0-4) & $2.5 \pm 1.2$ & $2.4 \pm 0.9$ & $2.0 \pm 1.2$ & $2.1 \pm 1.2$ & $2.3 \pm 1.1$ & $2.2 \pm 1.2$ \\
$\mathrm{BSA},(0-100 \%)^{\#}$ & $14.4 \pm 20.9$ & $6.8 \pm 9.9$ & $8.0 \pm 13.3$ & $8.8 \pm 15.0$ & $7.8 \pm 12.0$ & $9.9 \pm 15.8$ \\
Pain, (VAS 0-100) & $33.2 \pm 33.2$ & $20.3 \pm 24.8$ & $22.9 \pm 30.6$ & $21.9 \pm 28.0$ & $23.7 \pm 30.4$ & $25.6 \pm 30.8$ \\
Fatigue, (VAS 0-100) & $39.4 \pm 29.7$ & $36.3 \pm 33.1$ & $34.6 \pm 29.9$ & $33.4 \pm 27.5$ & $39.1 \pm 30.6$ & $37.0 \pm 29.9$ \\
Itch, (VAS 0-100) & $41.6 \pm 34.7$ & $34.6 \pm 31.4$ & $32.9 \pm 34.5$ & $33.5 \pm 32.8$ & $37.7 \pm 33.7$ & $36.7 \pm 33.9$ \\
EQ-VAS, (VAS 0-100) & $69.0 \pm 22.8$ & $68.5 \pm 23.4$ & $71.1 \pm 22.2$ & $71.0 \pm 20.3$ & $66.3 \pm 24.1$ & $69.0 \pm 22.7$ \\
DLQI (0-30) & $7.6 \pm 6.2$ & $5.6 \pm 5.5$ & $6.6 \pm 6.1$ & $7.4 \pm 7.1$ & $6.2 \pm 5.4$ & $6.8 \pm 6.1$ \\
WPAI - \% overall work & & & & & & \\
$\quad$ affected by Ps^ & $16.8 \pm 22.8$ & $19.8 \pm 23.8$ & $15.3 \pm 25.9$ & $12.8 \pm 21.5$ & $14.8 \pm 23.5$ & $15.5 \pm 23.8$ \\
\hline
\end{tabular}

${ }^{1}$ Data on infliximab and ixekizumab not presented due to small sample sizes; \#Mean scores were higher in incident users compared to prevalent users; *Non-biologics include: apremilast, cyclosporine, MTX; ^Assessed only in employed: $n=124$ (SEC); 37 (ETN); 121 (ADA); 98 (UST); 105 (Non-B); 510 (Overall).

Conclusions: These data show that Ps pts with concomitant PsA who initiated SEC in the Corrona Psoriasis Registry had higher disease activity, more comorbidities and suffered from more severe pain at enrolment. These differences need to be factored in for future analyses between treatment groups as data mature in this registry.

Disclosure of Interest: A. Gottlieb Grant/research support from: (Paid to Tufts Medical Center until 5/11/16, thereafter: None): Centocor (Janssen) Inc., Amgen, Abbott (AbbVie), Novartis, Celgene, Pfizer, Lilly, Levia, Merck, Xenoport, Dermira, Baxalta, Consultant for: Amgen Inc., Astellas, Akros, Centocor (Janssen) Inc., Celgene Corp., Bristol Myers Squibb Co., Beiersdorf Inc., Abbott Labs. (AbbVie), TEVA, Actelion, UCB, Novo Nordisk, Novartis, Dermipsor Ltd., Incyte, Pfizer, Canfite, Lilly, Coronado, Vertex, Karyopharm, CSL Behring Biotherapies for Life, Glaxo SmithKline, Xenoport, Catabasis, Meiji Seika Pharma Co. Ltd, Takeda, Mitsubishi, Tanabe Pharma Development America Inc., Genentech, Baxalta, Kineta One, KPI Therapeutics, Crescendo Bioscience, Aclaris, Amicus and Reddy Labs, V. Strand Consultant for: AbbVie, Amgen, BMS, Celgene, Celltrion, Corrona, Crescendo, Genentech/Roche, GSK, Janssen, Lilly, Merck, Novartis, Pfizer, Regeneron, Samsung, Sanofi and UCB, C. Karki Employee of: Corrona, LLC., M. Mason Employee of: Corrona, LLC., J. Greenberg Shareholder of: Corrona, LLC., Consultant for: AstraZeneca, Celgene, Genentech, Janssen, Novartis and Pfizer, Employee of: Corrona, LLC., S. Jugl Shareholder of: Novartis, Employee of: Novartis, K. Gandhi Shareholder of: Novartis, Employee of: Novartis, P. Mease Grant/research support from: AbbVie, Amgen, BMS, Celgene, Crescendo Bioscience, Genentech, Janssen, Lilly, Merck, Novartis, Pfizer, and UCB, Consultant for: Abbvie, Amgen, BMS, Celgene, Crescendo Bioscience, Genentech, Janssen, Lilly, Merck, Novartis, Pfizer, and UCB, Speakers bureau: AbbVie, Amgen, BMS, Celgene, Crescendo Bioscience, Genentech, Janssen, Lilly, Merck, Novartis, Pfizer and UCB

DOI: 10.1136/annrheumdis-2017-eular.2948 